A história da matemática e o lúdico pedagógico na aprendizagem em matemática

Denise Aparecida Enes Ribeiro

\title{
A HISTÓRIA DA MATEMÁTICA E O LÚDICO PEDAGÓGICO NA APRENDIZAGEM EM MATEMÁTICA
}

\author{
THE HISTORY OF MATHEMATICS AND THE PEDAGOGICAL PLAYER IN \\ LEARNING IN MATHEMATICS
}

\author{
Denise Aparecida Enes Ribeiro ${ }^{1}$ \\ Universidade Regional do Cariri- URCA
}

\begin{abstract}
Resumo
Este artigo refere-se a um recorte da dissertação de mestrado dessa autora, cujo objetivo foi analisar como a utilização de atividades de ensino de natureza interdisciplinar e lúdico pedagógicas, a partir da História da Matemática poderia contribuir para a melhoria da aprendizagem em Matemática. Para isso fizemos uma revisão bibliográfica de autores que tem se debruçado do sobre essa temática. Entre eles: Mendes (2015), Miguel, (2009), Boyer (1996), Miguel e Chaquian (2016) e Barbosa (2015). A pesquisa teve caráter qualitativo cujo foco é o indivíduo com toda sua complexidade e na sua inserção e interação com o ambiente sociocultural. Para o desenvolvimento desse trabalho atuamos com a pesquisa-ação e como instrumento de análise foi utilizado: coletas de dados, entrevistas e questionários com professores e alunos, não só para coleta de dados, mas análise reflexiva sobre o desenvolvimento da pesquisa e dos objetivos a serem alcançados. Realizamos também um Mini Curso em escola pública da região do Cariri Cearense, com alunos dos anos Finais do Ensino Fundamental em que foi aplicado os jogos Mancala e Quadrados Mágicos. O registro se deu por fotografias e questionários com os envolvidos na pesquisa. Como resultado dessa pesquisa foi elaborado um relatório onde os dados da realidade coletados juntamente com a experiência vivida através das propostas de atividades, foram aprofundados. Pudemos perceber que o uso da História da Matemática começa a se tornar mais frequente ainda que timidamente em sala de aula e que a utilização de lendas de caráter histórico, associados ao lúdico proporcionado pelos jogos relacionados a estas lendas puderam promover uma maior Motivação na aprendizagem da Matemática, colaborando na superação de uma visão eurocentrista dessa ciência.
\end{abstract}

Palavras-chave: História da Matemática; Lúdico-Pedagógico.

\begin{abstract}
This article refers to a clipping of the author's master's dissertation, whose objective was to analyze how the use of pedagogical and interdisciplinary educational activities from the History of Mathematics could contribute to the improvement of mathematics learning. For this we made a bibliographical review of authors who has been looking into this theme. Among them: Mendes (2015), Miguel (2009), Boyer (1996), Miguel and Chaquian (2016) and Barbosa (2015). The research had a qualitative character whose focus is the individual with all its complexity and its insertion and interaction
\end{abstract}

\footnotetext{
${ }^{1}$ denirriber07@hotmail.com 
with the socio-cultural environment. For the development of this work we worked with action research and as an instrument of analysis was used: data collection, interviews and questionnaires with teachers and students, not only for data collection, but reflective analysis on the development of research and objectives be achieved. We also held a Mini Course in a public school in the region of Cariri Cearense, with students from the final years of elementary school in which the games Mancala and Magic Squares were applied. Registration was by photographs and questionnaires with those involved in the research. As a result of this research, a report was elaborated where the reality data collected along with the experience lived through the proposed activities were deepened. We could see that the use of the History of Mathematics is starting to become more frequent even though shyly in the classroom and that the use of historical legends, associated with the playfulness provided by the games related to these legends, could promote a greater motivation in the learning of mathematics. Mathematics, helping to overcome a Eurocentric view of this science.

Keywords: History of Mathematics; Playful-Pedagogical.

\section{Introdução}

Este artigo busca trazer uma parte das discussões realizadas em dissertação de Mestrado: "História da Matemática: a Interdisciplinaridade e o Lúdico Pedagógico na Aprendizagem em Matemática". A nossa preocupação foi a de nos debruçarmos na perspectiva de ensinar a matemática do ponto de vista de sua historicidade e que a História da Matemática tem se firmado como uma tendência metodológica em Educação Matemática. Temos, em Mendes (2015), Chaquian (2016), Barbosa (2013) e Fauvel (1991), alguns exemplos dessa preocupação. Este interesse pela utilização da História da Matemática nasceu da investigação da própria prática enquanto docente de escola pública e posteriormente no ensino superior. Observando os livros didáticos que traziam tópicos relativos à vida de matemáticos famosos, podíamos observar o interesse dos alunos. Observávamos que este tipo de abordagem tinha um valor como sensibilização inicial. Pesquisando mais esta tendência, pudemos observar então outros tipos de abordagem ao uso da História da Matemática em atividades didáticas.

Outra motivação de ordem pessoal foi nossa admiração pela obra de Júlio César de Mello e Souza, nosso Malba Tahan. Como leitora e depois professora, fomos nos apercebendo de sua contribuição para a introdução da História da Matemática com fins pedagógicos e motivadores. Ele é considerado um precursor da História da Matemática no Brasil para fins didáticos e desempenhou junto com outros educadores como Euclides Roxo e Cécil Thirré, papel importante na tentativa de modernizar o ensino de Matemática de então (D’AMBROSIO, 2013). Seus livros mais notáveis nesse sentido são o famoso "Homem que Calculava" e "Matemática Divertida e Curiosa". 
Também Mendes (2015) nos aponta a necessidade de se ter uma linguagem clara e concisa na elaboração das atividades e que o uso da literatura poderia enriquecer a investigação histórica:

A literatura pode ser incluída como uma fonte suplementar de investigação histórica da matemática, pois constitui-se em uma fonte de informação que também oportuniza o desenvolvimento de atitude e prática criativa nas aulas de matemática caracterizada nos trabalhos de Malba Tahan, Lewis Carrol, Juan Perez Moya, Edwin A. Abbott, entre outros. (MENDES. p.205, 2015).

Buscando ainda referência nas considerações de Fauvel (1991), sobre a importância da História da Matemática no ensino, concordamos com o mesmo quando afirma que:

- a história aumenta a motivação para a aprendizagem da matemática;

- humaniza a matemática;

- mostra seu desenvolvimento histórico e como os conceitos matemáticos se desenvolveram;

- contribui para a mudança de concepção dos alunos em relação à matemática e a quebra de mitos;

- suscita oportunidades para a investigação e pesquisa em tópicos matemáticos. (FAUVEL, 1991, apud. MIGUEL, 2009. p. 9).

É nesse viés que buscaremos refletir sobre o uso da Historia da Matemática no ensino aprendizagem da Matemática, aliada a jogos que surgiram da própria cultura e que tenham uma ligação com a ciência matemática.

\section{História da Matemática como Motivação ao Ensino da Matemática}

Ao refletirmos sobre as razões para o estudo da História da Matemática, encontramos em Barbosa (2013) que o valor do conhecimento histórico para o professor de matemática pode gerar um maior interesse dos alunos por essa disciplina:

O interesse dos alunos em seus estudos pode ser significativamente aumentado se a solução dos problemas e a fria lógica das demonstrações forem temperadas com anedotas, textos históricos, notas históricas, biografias e muitos outros recursos. (BARBOSA, 2013. p. 17).

Embora este seja um dos objetivos, aumentar o interesse e a motivação na aprendizagem, porém nem sempre isso acontece com o uso da História da Matemática. Alguns fatores seriam que nem todos os alunos gostam de história, e se a atividade se resumir a dados bibliográficos e datas descontextualizadas, podem se tornar desestimulantes. Por isso temos que um dos aspectos do uso da História da Matemática 
em sala de aula é o seu caráter investigatório de conceitos construídos ao longo do tempo. Como nos afirma Mendes (2001):

A História da Matemática constitui-se em uma proposta que enfatiza o caráter investigatório do processo de construção da Matemática, levando os estudiosos dessa área de pesquisa à elaboração, testagem e avaliação de atividades de ensino centradas no uso de informações históricas referentes aos tópicos que pretendem investigar. (MENDES, 2001, p.15).

Mendes e Chaquian (2016) vem reforçar a ideia de que a História da Matemática não é apenas uma definição de objetos matemáticos, mas de um processo criativo que envolve sociedade, cultura e cognição; onde se busca através dessas histórias compreender o contexto histórico e científico no qual determinado conceito foi gerado e o desafio de se fazer uma adequada transposição didática do mesmo, sem idealizações dos personagens envolvidos, mas ressaltando-se seu lado humano, profundamente humano.

Os aspectos da vida cotidiana nos revelam muito historicamente. Mesmo as lendas e contos, embora tenham caráter de cultura oral e de difícil documentação, estabelecem-se como material rico para se compreender o pensamento de determinada sociedade e cultura em seu tempo histórico. As lendas as quais nos referimos principalmente são aquelas que retratam a criação ou utilização de determinados jogos cuja origem se perde no tempo, jogos que criados com a função de lazer acabaram também sendo uma forma dos oponentes comprovarem sua inteligência e capacidade estratégica.

Os autores Mendes e Chaquian (2016) também nos alertam sobre o fato de nem toda informação histórica ter potencial de aprendizagem matemática:

I) Histórias que retratam a vida de matemáticos e professores de matemática do ponto de vista somente biográficos acabam contribuindo apenas de forma ilustrativa. Aqueles alunos que não sentem interesse pela história, podem não ser motivados como o esperado. Trazer anedotas e curiosidades pode ser estimulante, mas nem todos os matemáticos que estudamos trazem histórias tão pitorescas, caindo novamente em textos apenas relativos a datas e obras descontextualizados.

II) Uso de Lendas e Mitologias deve- ser usado com cautela pelo professor. São encontrados em livros de literatura e paradidáticos e baseados muitas vezes em fontes não seguras ou que apostam no imaginário. 
O professor poderá utilizar de tal material desde que saiba explorar o seu potencial imaginativo e estimular o exercício de problematização dos alunos, bem como sua capacidade criativa para criar alguma matemática e conectálas ao conteúdo programático previsto no planejamento do professor. (MIGUEL; CHAQUIAN, p. 20. 2016).

III) O uso inadequado de narrativas históricas sobre nomes, datas e locais sem configurar o desenvolvimento de conceitos, propriedades e relações matemáticas. Novamente o professor, como mediador do processo de ensino aprendizagem, deve redimensionar tais narrativas e modo a agregar o desenvolvimento de conceitos e por fim fazer a sistematização das ideias matemáticas que são necessárias formalizar naquele determinado momento.

Como se pode observar tudo depende da forma como o professor irá trabalhar a atividade que envolve a História da Matemática e das Tendências didático pedagógicas que seja mais simpatizante. Particularmente, o processo ao qual queremos nos ater, é o de cunho construtivista e sócio interacionista, onde a História da Matemática seria nosso aporte para que os alunos compreendessem a matemática como produção cultural humana, não só de um povo, mas de vários, contribuindo assim para a superação da visão eurocentrista da ciência e valorização das etnomatemáticas.

Também nos PCN's encontramos vários momentos em que o uso de metodologias alternativas em matemática seria um material valioso:

\begin{abstract}
Apresentada em várias propostas como um dos aspectos importantes da aprendizagem matemática, por propiciar compreensão mais ampla da trajetória dos conceitos e métodos das ciências, a História da Matemática também tem se transformado em assunto específico, um item a mais a ser incorporado ao rol dos conteúdos, que muitas vezes não passa da apresentação de fatos ou biografias de matemáticos famosos. (BRASIL, 1998.p. 23).
\end{abstract}

Os PCN's fazem uma crítica ao afirmar que o uso da História da Matemática embora valioso, seria apenas um item a mais caso se contentasse em apenas apresentar fatos e biografias de matemáticos famosos de uma forma descontextualizada dos conceitos a serem trabalhados em sala. Este enfoque exclusivo como já vimos, já foi criticado pelos autores citados anteriormente.

\title{
A interação entre a História da Matemática e o Lúdico Pedagógico
}

A História da Matemática pode ser abordada a partir dos jogos criados pela humanidade e que tiveram um papel social e histórico no qual surgiram. Esses jogos 
serviram inicialmente para o lazer, o lúdico, mas também como aporte para a descrição e pesquisa em conceitos matemáticos que emergem da própria utilização do jogo.

Suas lendas originárias e mitos relacionados servem justamente para a compreensão por parte do aluno desta grande capacidade humana de criação e superação, da grandeza de nossa espécie e de que o conhecimento não é propriedade de uma só civilização, mas de várias, que historicamente foram sendo menos valorizadas.

A Mancala, os Quadrados Mágicos, o Tangram, o Xadrez e a Torre de Hanói, são jogos onde a interdisciplinaridade com a Língua Portuguesa e a História pode se dar através da inicial leitura da lenda relativa ao jogo, seguida de uma contextualização histórica e do desenvolvimento matemático do povo em questão. A aprendizagem do jogo deve ocorrer de forma espontânea, sem retirar dele o aspecto lúdico inicial, porém os conceitos matemáticos relacionados deverão ser trabalhados para que o objetivo de aprendizagem através da atividade seja alcançado.

A História da Matemática tem esse potencial então de integração: entre os ramos da própria matemática e desta com outras disciplinas. Esta interdisciplinaridade entre a matemática e disciplinas poderia então ocorrer através destas atividades com os jogos: Matemática e Língua Portuguesa, Matemática e História, Matemática e Meio Ambiente e Matemática e Diversidade Cultural, mesmo sendo estes últimos tópicos, não propriamente disciplinas escolares, mas Temas Transversais.

Aqui vale, novamente as considerações dos professores pela falta de tempo e de propostas pedagógicas para sua implementação. Essa questão nos aponta uma falha na formação inicial e continuada do professor de matemática. Com relação ao tempo, novamente há as cobranças externas para que o professor se atenha a cumprir o conteúdo solicitado e que será exigido como proficiência em provas externas.

Estudando o termo bricolagem (grifo nosso) que é citado na obra de Iran Mendes (2015), o mesmo busca reinventar possibilidades para a realização de práticas matemáticas significativas junto com os docentes, tomando suas experiências cotidianas como referência e os materiais disponíveis para a realização das aulas práticas; percebemos que nossa pesquisa também vai nesta direção, numa perspectiva interdisciplinar e buscando a transdisciplinaridade.

O termo bricolagem deriva da palavra em francês bricoleur, utilizada por Claude Lévi-Strauss (2002), para explicar a habilidade do artesão em juntar diferentes objetos de que dispõe e assim obter nova peça. Iran Mendes afirma: 
O objetivo primordial das pesquisas que realizo é que o conhecimento produzido convirja para a sala de aula. A esse respeito, guardo comigo a esperança de que o professor possa vir a ter uma postura transdisciplinar na sua prática educativa. Tal postura poderá valorizar a pluralidade de conhecimentos das sociedades e das novas formas de ensinar os conteúdos de matemática nas escolas. Daí minhas apostas em religar a matemática com outros saberes como a Arte, a Música, a Dança, a Arquitetura, a Literatura e os saberes da tradição. Como sabemos, o exercício de religar áreas distintas e complementares do conhecimento exige um ritmo de estudo constante, para que o sujeito possa estabelecer diálogos criativos sobre temas que vão além de sua área de pertencimento profissional. (MENDES, p. 71. 2015).

As atividades que propomos, podem se tornar um exercício desta bricolagem (grifo nosso) no sentido acima assumido, pois ao trabalharmos com os jogos relacionados à História da Matemática, estaremos "religando" conhecimentos que tem sido considerado distantes uns dos outros, na velha dicotomia Humanas x Exatas. Literatura, História e Matemática, além de Meio Ambiente.

Estaremos então fazendo o resgate de uma matemática que tem em sua origem a cultura dos povos relacionada aos jogos estudados e à matemática que está inserida neste contexto cultural, tornando assim este estudo vivo e com significado para o estudante.

A abordagem dos tópicos matemáticos a partir de diferentes contextos socioculturais (étnicos) pode conduzir a um processo de compreensão dos aspectos matemáticos desenvolvidos pelas diversas sociedades do planeta, evidenciando assim, o caráter universalizante e globalizante da matemática. (MENDES, p. 73. 2015).

Segundo D’Ambrosio (2011) a disciplina que hoje denominamos de Matemática é na verdade uma etnomatemática que se originou e desenvolveu na Europa, tendo recebido algumas contribuições das civilizações indiana e islâmica, e que chegou à forma atual nos séculos XVI e XVII e então foi levada e imposta a todo mundo a partir do período colonial.

Atualmente a mesma adquire um caráter de universalidade, sobretudo em virtude do predomínio da ciência e tecnologia modernas, desenvolvidas a partir do século XVII na Europa. Este mesmo autor afirma que ao nos referirmo-nos a ciência Matemática, estamos falando na verdade de uma Matemática dominante, que é um instrumento desenvolvido nos países centrais e que muitas vezes foi utilizado como forma de dominação dos povos dominados. A essência de sua proposta é:

Uma educação universal, atingindo toda a população, proporcionando a todos o espaço adequado para o pleno desenvolvimento de 
criatividade desinibida, que ao mesmo tempo em que preserva a diversidade e elimina as inequidades, conduz a novas formas de relações intraculturais e interculturais sobre as quais se estruturam novas relações sociais e uma nova organização planetária. (D’AMBROSIO, p. 110. 2012).

Comungamos da visão de D'Ambrosio sobre a educação e em especial sobre a educação matemática e esperamos que nossa proposta de atividade realizada nesta pesquisa possa contribuir para se alcançar estas novas relações e estruturas sociais apontadas.

Esperamos ainda que o velho eurocentrismo vá sendo substituído por uma visão da ciência e da própria matemática de uma maneira mais global, respeitando as contribuições que diversos povos fizeram e assim resgatando também a autoestima do aluno ao se identificar com uma matemática que se torna não tão inatingível, pois já teria sido fruto da reflexão ativa de diversas culturas e não só a hegemônica europeia.

\section{Como os Professores Trabalham a História da Matemática}

Fizemos junto a um pequeno universo de professores da região do Cariri (Crato e Juazeiro do Norte) um questionário, do qual apresentaremos somente algumas perguntas e respostas consoantes com nossos objetivos com esse artigo.

Uma das questões foi sobre quais eram as técnicas ou metodologias mais usadas em sala de aula. As alternativas que mais se destacaram foram: aula expositiva com lista de exercícios (9), seguida de resolução de problemas e jogos ou matemática recreativa (8).

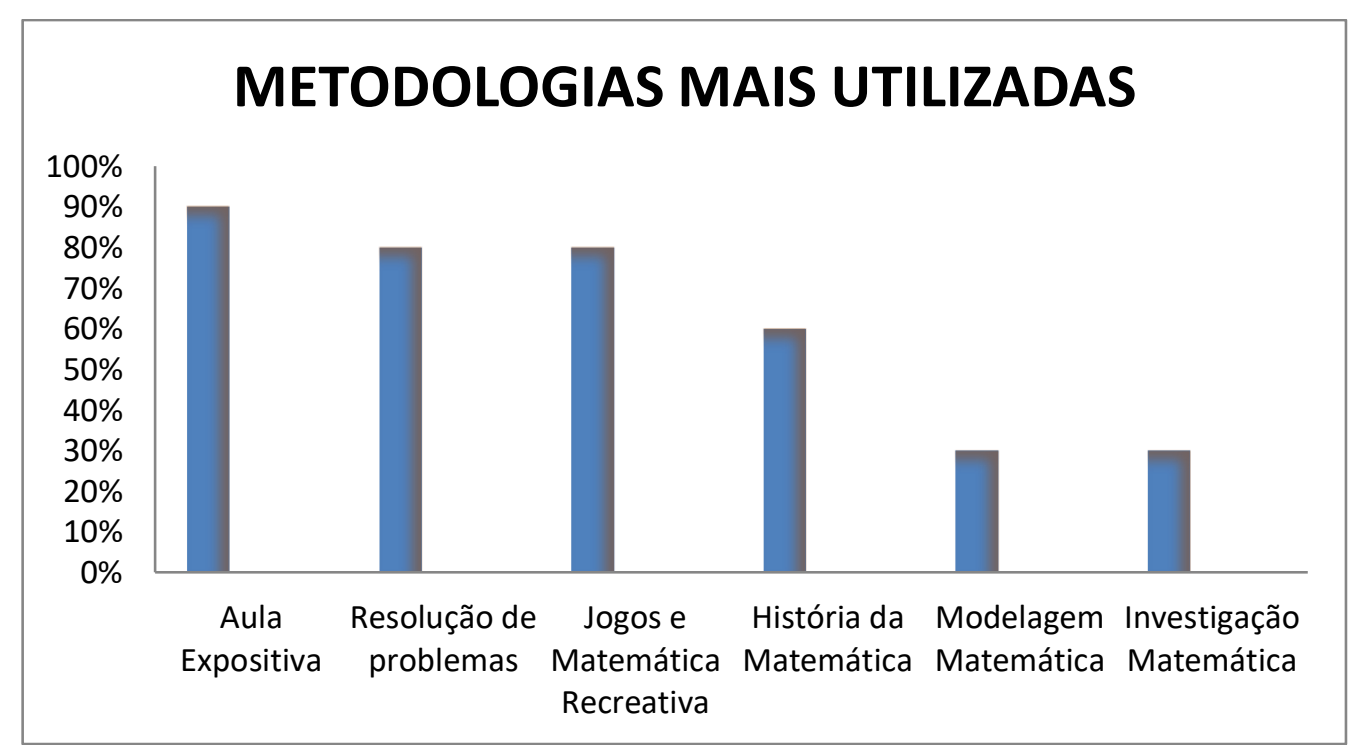

Figura 1 - Gráfico sobre as Metodologias Mais Usadas pelos Professores

Fonte: Denise Ribeiro, 2019. 
O fato de aulas expositivas com lista de exercícios serem citada por quase todos os professores só vem ressaltar aquilo que Ole Skovsmose (2007) chama de Paradigma do Exercício, onde há uma redução da matemática escolar a esta prática praticamente hegemônica com raras exceções. Segundo Skovsmose, o número de exercícios resolvidos por um aluno durante sua vida escolar chegaria a 10.000, apresentados em forma de comandos, que em nada colaborariam para o desenvolvimento da criatividade e do pensar matemático, muito menos de raciocínio lógico, "Contudo, eles devem ter algumas similaridades com outras tarefas rotineiras que algumas vezes são encontradas na produção e administração" (SKOVSMOSE, 2007. p. 37).

O segundo e o terceiro lugar são respectivamente: resolução de problemas e jogos e matemática recreativa. Muito nos alegra, serem citados, mas não nos aprofundamos de que maneira e frequência essas metodologias estariam sendo empregadas.

A terceira opção mais assinalada foi por fim a História da Matemática (6) e perguntamos sobre como a mesma era utilizada em sala de aula. A maioria respondeu que sim (9 professores) - destes dois afirmaram que algumas vezes- e apenas um professor afirmou que não. Os exemplos são mais elucidativos:

- História dos Números, sistemas numéricos, outras civilizações (egípcios), e operações básicas - 4;

- História da Matemática envolvendo Tales e Pitágoras - 2;

- Números e pesquisas - 1

- No início de cada capítulo para aguçar a curiosidade -1;

- Apresentação de vídeos com exploração matemática - 1;

- Sólidos Geométricos - 1.

Percebe-se com essa resposta dos (as) professores (as) que a H.M ainda é subutilizada nas aulas de matemática, apesar de ter sido assinalada por 6 professores anteriormente. A maioria ainda se detém na H.M dos sistemas numéricos e na geometria o que já é um avanço que acredito estar ligado ao fato da importância da H.M estar sendo paulatinamente assimilada pelos professores, porém ainda falta por parte dos professores, mais alternativas pedagógicas de como trabalhar esta tendência em sala.

Temos em Barbosa (2013) a constatação de que as tentativas de se inserir a H.M nas aulas aumentaram, e um das formas de inseri-la senão a única é através de um dos recursos mais utilizados senão o único: o Livro Didático. Este autor após estudo sobre a inserção de H.M em livros didáticos pela avaliação de resenhas do GLD (Guia de 
A história da matemática e o lúdico pedagógico na aprendizagem em matemática

Denise Aparecida Enes Ribeiro

Livros Didáticos, 2002), concluiu que esta inserção estava aumentando consideravelmente principalmente na questão da contextualização e que isso seria um fator importante para auxiliar aqueles professores que não tiveram em sua formação a oportunidade de integralizar conhecimentos sobre a História da Matemática (BARBOSA, 2013).

Apenas dois professores responderam negativamente e a justificativa para isso foi uma insegurança na parte técnica e a cobrança por resultados das instâncias superiores. Estas respostas negativas nos apontam o excesso de cobrança que os professores sofrem por bons resultados, onde o fator tempo acaba sendo decisivo na escolha de alternativas metodológicas, onde este professor acaba se conformando ao uso de apenas um recurso: o livro didático, e como esses em geral abordam pouco a H.M (embora esta realidade tenha melhorado conforma nos aponta Barbosa, 2013) o professor também a deixa em segundo plano.

\section{Resultados e Conclusões}

Este trabalho, que agrega a investigação histórica e jogos, promoveu nos alunos muito interesse e motivação na participação do Mini curso sobre Mancala e Quadrados Mágicos, conforme a análise dos resultados e suas respostas ao questionário final, que se encontra melhor detalhado no relatório da dissertação a qual nos referimos.

Com relação aos professores que responderam ao questionário e a professora regente, podemos destacar que a prática de inserir a História da Matemática em sala de aula, ainda é muito pequena, mas há iniciativas, ainda que solitárias. Essas iniciativas revelam a percepção dos professores da importância da História da Matemática e da interdisciplinaridade, porém ainda muito presos a projetos realizados pela escola, e nem sempre definidos coletivamente, ou propostos pelo próprio professor de matemática, que ainda ao trabalhar o que ele julga ser a interdisciplinaridade, o faz voltados em atividades de exploração de tabelas, gráficos e dados estatísticos. A própria História da Matemática, vem sendo trabalhada também timidamente, quando é trabalhada.

Apontamos a necessidade de se investir mais tempo nos cursos de formação continuada e inicial de professores em se inserir um embasamento teórico mais consistente em relação a estes tópicos. Não é possível deixar ao próprio professor, por mais que seja compromissado, toda a responsabilidade por procurar formas inovadoras de se trabalhar o ensino aprendizagem de matemática, sem o devido apoio. 
A história da matemática e o lúdico pedagógico na aprendizagem em matemática Denise Aparecida Enes Ribeiro

Como resultado, verificamos a possibilidade concreta de que a utilização de lendas de caráter histórico, associados ao lúdico proporcionado pelos jogos relacionados a estas lendas podem promover uma maior Motivação na aprendizagem da Matemática, e uma adesão consciente por parte dos alunos em sua própria aprendizagem.

O Eurocentrismo vai caindo por terra, ao se perceber a contribuição de vários povos ao crescimento dessa ciência e assim o aluno, assume-se tão capaz como aquele povo, seja africano, chinês ou indiano, que ele nem imaginava ser tão competente matematicamente como os europeus. Há uma identificação e sua autoestima cresce podendo imaginar que ele (ela) jovem da periferia também pode aprender e fazer matemática.

É necessário, portanto, que se avance cada vez em pesquisas sobre a utilização da História da Matemática em atividades práticas e lúdicas e de como estas atividades podem proporcionar a Interdisciplinaridade entre Matemática, História, Língua Materna e Geografia de forma a quebrar a velha visão eurocêntrica da ciência e de promover a aprendizagem de nossos alunos numa perspectiva ética e universal.

\section{Referências}

BRASIL, Secretaria de Educação Fundamental. Parâmetros Curriculares Nacionais: matemática. Brasília: MEC/SEF 1998a.

BRASIL, Secretaria de Educação Fundamental. Parâmetros Curriculares Nacionais do Ensino Médio: matemática. Brasília: MEC/SEB 1999.

BRASIL, Secretaria de Educação Fundamental. Parâmetros Curriculares Nacionais: temas transversais. Brasília: MEC/SEF 1998b.

BARBOSA, J.L.C. A Participação da História da Matemática em Livros Didáticos. VII CIBEM. Montevidéu, Uruguai, 16 a 20 de setembro de 2013.

CHAQUIAM, M. Ensaios Temáticos: História e Matemática em Sala de Aula. Belém, SBEM/SEBEM-PA, 2017.

D’AMBROSIO, U. Educação Matemática, da Teoria á Prática. 23. Ed. Campinas, São Paulo, Papiros, 2012.

FAZENDA, I. C. Arantes. O que é interdisciplinaridade? São Paulo, Cortez. 2008.

MENDES, I. A. História da matemática no Ensino: entre trajetórias profissionais, epistemologias e pesquisas. São Paulo. Editora Livraria da Física, 2015. 
A história da matemática e o lúdico pedagógico na aprendizagem em matemática

Denise Aparecida Enes Ribeiro

MENDES, I.A; CHAQUIAM. M. História nas Aulas de Matemática: fundamentos e sugestões didáticas para professores. Belém: SBHMAT, 2016.

MIGUEL, A. [et, al]- História da Matemática em Atividades Didáticas - $2^{\mathrm{a}}$ ed. Revista. São Paulo. Editora Livraria da Física, 2009.

PEREIRA, R. P. Cunha Jr., H. Mancala: o jogo africano no ensino da matemática. $1^{\text {a }}$ ed. Curitiba: Appris, 2016.

SKOVSMOSE, O. Educação Matemática Crítica a questão da Democracia. Trad: Jussara Loiola Araújo e Abgail Lins. São Paulo, Papirus, 2001.

SOARES, E. S. Ensinar matemática, desafios e possibilidades. Belo Horizonte: Dimensão, 2009.

TAHAN, M. O Homem que Calculava. 29. Ed. Record. Rio de Janeiro. 1985. 